\title{
Fish consumption and breast cancer risk. The European Prospective Investigation into Cancer and Nutrition (EPIC)
}

\author{
Dagrun Engeset $^{1 *}$, Elin Alsaker ${ }^{1}$, Eiliv Lund ${ }^{1}$, Ailsa Welch ${ }^{2}$, Kay-Tee Khaw ${ }^{3}$, Françoise Clavel-Chapelon ${ }^{4}$, \\ Anne Thiébaut ${ }^{4}$, Véronique Chajès ${ }^{5}$, Timothy $\mathrm{J} \mathrm{Key}^{6}$, Naomi E Allen ${ }^{6}$, Pilar Amiano ${ }^{7}$, Miren Dorronsoro ${ }^{7}$, \\ Anne Tjønneland $^{8}$, Connie Stripp ${ }^{8}$, Petra HM Peeters', Carla H van Gils', Maria-Dolores Chirlaque ${ }^{10}$, \\ Gabriele Nagel $^{11}$, Jakob Linseisen ${ }^{11}$, Marga C Ocké ${ }^{12}$, H Bas Bueno-de-Mesquita ${ }^{12}$, Carlotta Sacerdote ${ }^{13}$, \\ Rosario Tumino ${ }^{14}$, Eva Ardanaz ${ }^{15}$, Maria-Jose Sánchez ${ }^{16}$, Salvatore Panico ${ }^{17}$, Domenico Palli ${ }^{18}$, \\ Antonia Trichopoulou ${ }^{19}$, Victoria Kalapothaki ${ }^{19}$, Vicky Benetou ${ }^{19}$, J Ramón Quirós ${ }^{20}$, Antonio Agudo ${ }^{21}$, \\ Kim Overvad $^{22}$, Lone Bjerregaard ${ }^{23}$, Elisabet Wirfält ${ }^{24}$, Mandy Schulz ${ }^{25}$, Heiner Boeing ${ }^{25}$, \\ Nadia Slimani ${ }^{26}$ and Elio Riboli ${ }^{26}$ \\ ${ }^{1}$ Institute of Community Medicine, University of Troms $\phi$, Troms $\phi$, Norway \\ ${ }^{2}$ Department of Public Health and Primary Care, School of Clinical Medicine, University of Cambridge, \\ Cambridge, United Kingdom \\ ${ }^{3}$ Clinical Gerontology Unit, School of Clinical Medicine, University of Cambridge, Cambridge, United Kingdom \\ ${ }^{4}$ INSERM, E3N-EPIC, Institut Gustave Roussy, Villejuif, France \\ ${ }^{5}$ CNRS, UMR 8125, Institut Gustave Roussy, Villejuif, France \\ ${ }^{6}$ Cancer Research UK, Epidemiology Unit, University of Oxford, Oxford, United Kingdom \\ ${ }^{7}$ Public Health Division of Gipuzkoa, Health Department of the Basque Country, San Sebastian, Spain \\ ${ }^{8}$ Institute of Cancer Epidemiology, Danish Cancer Society, Copenhagen, Denmark \\ ${ }^{9}$ Julius Centre for Health Sciences and Primary Care, University Medical Center Utrecht, Utrecht, the Netherlands \\ ${ }^{10}$ Epidemiology Department, Murcia Health Council, Murcia, Spain \\ ${ }^{11}$ Division of Clinical Epidemiology, Deutsches Krebsforschungszentrum, Heidelberg, Germany \\ ${ }^{12}$ Centre for Nutrition and Health, National Institute of Public Health and the Environment, \\ Bilthoven, the Netherlands \\ ${ }^{13}$ CPO-Piemonte, Turin, Italy \\ ${ }^{14}$ Cancer Registry, Azienda Ospedaliera Civile M.P. Arezzo, Ragusa, Italy \\ ${ }^{15}$ Public Health Institute of Navarra, Pamplona, Spain \\ ${ }^{16}$ Andalusian School of Public Health, Granada, Spain \\ ${ }^{17}$ Department of Clinical and Experimental Medicine, Federico II University, Naples, Italy \\ ${ }^{18}$ Molecular and Nutritional Epidemiology Unit, CSPO-Scientific Institute of Tuscany, Florence, Italy \\ ${ }^{19}$ Department of Hygiene and Epidemiology Medical School, University of Athens, Greece \\ ${ }^{20}$ Public Health and Health Planning Directorate, Asturias, Spain \\ ${ }^{21}$ Unit of Epidemiology, Catalan Institute of Oncology, Barcelona, Spain \\ ${ }^{22}$ Department of Clinical Epidemiology, Aalborg Hospital, Aarhus University Hospital, Aalborg, Denmark \\ ${ }^{23}$ Department of Preventive Cardiology, Aalborg Hospital, Aarhus University Hospital, Aalborg, Denmark \\ ${ }^{24}$ Department of Clinical Sciences, Lund University, Malmö, Sweden \\ ${ }^{25}$ German Institute of Human Nutrition Potsdam-Rehbrücke, Nuthetal, Germany \\ ${ }^{26}$ International Agency for Research on Cancer (IARC-WHO), Lyon, France
}

There is current interest in fish consumption and marine omega-3 (n3) fatty acids and breast cancer risk. Some in vitro and animal studies have suggested an inhibitory effect of marine $\mathbf{n}-3$ fatty acids on breast cancer growth, but the results from epidemiological studies that have examined the association between fish consumption and breast cancer risk in humans are inconsistent. We examined fish consumption and breast cancer risk in 310,671 women aged between 25 and $70 \mathrm{yr}$ at recruitment into the European Prospective Investigation Into Cancer and Nutrition (EPIC). The participants completed a dietary questionnaire between 1992-98 and were followed up for incidence of breast

Abbreviations: CI, confidence interval; EPIC, European Prospective Investigation into Cancer and Nutrition; FFQ, food frequency questionnaires; FTP, full-term pregnancies; HA, heterocyclic amines; 24-HDR, 24 hr dietary recall; HR, hazard ratio; HRT, hormone replacement therapy; IARC, International Agency for Research on Cancer; n-3, omega 3; n-6, omega 6; OC, oral contraceptives; OR, odds ratio; $\mathrm{PAH}$, polycyclic aromatic hydrocarbons; SE, standard error; WHO, World Health Organization.

Grant sponsor: Europe Against Cancer Program of the European Commission (SANCO), Deutsche Krebshilfe, Deutsches Krebsforschungszentrum, German Federal Ministry of Education and Research, Danish Cancer Society, Health Research Fund (FIS) of the Spanish Ministry of Health, Spanish Regional Governments of Andalucia, Asturia, Basque Country (Murcia and Navarra), The ISCIII Network RCESP (C03/09) (Spain), Cancer Research UK, Medical Research Council (United Kingdom), Stroke Association (United Kingdom), British Heart Foundation, Department of Health (United Kingdom), Food Standards Agency (United Kingdom), Welcome Trust cancer for a median of 6.4 yr. Hazard ratio for breast cancer by intake of total and lean and fatty fish were estimated, stratified by study centre and adjusted for established breast cancer risk factors. During follow-up, 4,776 invasive incident breast cancers were reported. No significant associations between intake of total fish and breast cancer risk were observed, hazard ratio (HR) 1.01 (95\% confidence interval $[\mathrm{CI}]$ 0.99-1.02; $p=0.28$ per $10 \mathrm{~g}$ fish/day). When examining lean and fatty fish separately, we found a positive significant association only in the highest quintile for fatty fish (HR 1.13, 95\% CI 1.01-1.26), but test for trend was not significant ( $p=0.10$ ).
(United Kingdom), Italian Association for Research on Cancer (AIRC), Compagnia di San Paolo (Italy), Dutch Ministry of Public Health, Welfare and Sports, World Cancer Research Fund, Norwegian Cancer Society, Research Council of Norway, French League against Cancer (LNCC), National Institute for Health and Medical Research (INSERM) (France), Mutuelle Générale de 1'Education Nationale (MGEN) (France), 3M Company, France, Greek Ministry of Health, Greek Ministry of Education, Swedish Cancer Society, Swedish Research Council, Regional Government of Skåne.

*Correspondence to: Institute of Community Medicine, University of Troms $\varnothing$, N-9037 Troms $\varnothing$, Norway. Fax: +47 22851313

E-mail: dagrun.engeset@ism.uit.no 
No associations with breast cancer risk were observed when the study participants were subdivided by menopausal status. Although the period of follow-up is relatively short, the results provide no evidence for an association between fish intake and breast cancer risk.

Fish consumption provides a valuable nutritional contribution of protein of high biological value, unsaturated essential fatty acids, as well as certain vitamins and minerals. According to the World Health Organization (WHO), there is inconclusive evidence that increased consumption of fish and omega-3 (n-3) fatty acids from fish is effective in preventing cancer. ${ }^{1}$ Nevertheless, there is current interest in potential benefits or risks related to fish consumption, marine n-3 fatty acids and breast cancer development. ${ }^{2-4}$ In vitro and animal studies have shown inhibitory effects of marine n-3 fatty acids on breast cancer growth. ${ }^{5,6}$ Several epidemiological studies have examined the association between fish consumption and breast cancer risk in humans. In a review of 7 cohort studies and 19 case-control studies examining fish consumption, marine n-3 fatty acids and breast cancer risk, Terry et al. ${ }^{4}$ reported inconsistent results. Some studies found no association, while others found a decreased risk with high consumption of fish or n-3 fatty acids, and some studies found an inverse association only for subgroups defined by menopausal status and estrogen receptor status. ${ }^{4}$ One of the studies in the review, a study by Holmes et al., ${ }^{7}$ found a slightly increased risk of breast cancer associated with higher dietary marine n-3 fatty acids in a cohort study with 88,795 women. A more recent study by Gago-Domingue $\mathrm{z}^{8}$ found a significantly reduced risk of breast cancer in those with a high consumption of fish and marine n-3 fatty acids in The Singapore Chinese Health Study, a prospective cohort study with 314 breast cancer cases. Similarly, a significant inverse association between fish intake and breast cancer risk has been observed in Japanese women (2,385 breast cancer cases, 19,013 in reference group, with odds ratio (OR) $0.75,95 \%$ confidence interval (CI) $0.57-0.98) .{ }^{9}$ A limitation in most studies on fish consumption and breast cancer risk is that they do not distinguish between lean and fatty fish. Lean fish contains only small amounts of n-3 fatty acids, since most of the fat is stored in the fish liver. If there is a beneficial effect of $\mathrm{n}-3$ fatty acids it may be that an association is only apparent for fatty fish consumption. However, Terry et al. ${ }^{10}$ examined the association between fatty and lean fish and breast cancer risk in a large nationwide case-control study in Sweden. They found only weak, but not significant inverse association with fish and breast cancer and did not find any clear difference according to type of fish. There was no association between salmon consumption and breast cancer risk in the Norwegian Women and Cancer Study. ${ }^{11}$ Stripp et al. ${ }^{12}$ found a positive association with total fish intake and breast cancer risk, but no differences in association according to type of fish or preparation method, and suggested that there might be other factors in fish intake apart from n-3 fats that might have been responsible for this finding.

The European Prospective Investigation into Cancer and Nutrition (EPIC) study is a large multicentre cohort study on diet, lifestyle and other environmental factors and cancer conducted in 23 centres in 10 European countries. Analyses based on 24-hr dietary recalls (24-HDR) have shown large differences on fish consumption between the countries, with highest intake of fish in the Spanish and Norwegian centres for women. ${ }^{13}$ The difference in the amount of fish consumed is mainly due to cultural tradition and availability of fresh fish in the different countries and centres. ${ }^{13}$ However, the differences within the EPIC countries in fish intake are not only in the amount of fish consumed but also in the different types of fish (lean or fatty), species (cod, salmon, mullet, etc.), preparation methods (frying, deep frying, poaching, etc.) and how fish is consumed (with sauce, vegetables, salted, etc.). This heterogeneity provides a unique opportunity to examine fish consumption in relation to different diseases. ${ }^{13}$
In the present study, we examined fish consumption and breast cancer risk in EPIC, according to the type of fish consumed.

\section{Material and methods}

The EPIC study is an ongoing multicentre study designed to investigate the relationship between diet or dietary habits, nutrition, lifestyle and environmental factors and the incidence of cancer of various sites. The total EPIC cohort includes 519,978 participants from 23 centres in 10 European countries (Denmark, France, Germany, Greece, Italy, the Netherlands, Norway, Spain, Sweden and the United Kingdom), which makes it possible to compare different rates of cancer occurrence, distribution of lifestyle and food habits between regions. Data were collected by administration of questionnaires about different dietary and lifestyle habits at time of enrolment. The age range of the participants was predominantly from 35-70 yr. The participants were recruited from the general population living in a specific geographical region, a town, a province or country. Exceptions were the French cohort (female members of the health insurance for state school employees), the Utrecht cohort, Netherlands (women attending breast cancer screening), the Ragusa cohort, Italy (blood donors and their spouses) and most of the Oxford cohort, UK (vegetarians and health-conscious volunteers). Riboli et al. ${ }^{14}$ have described the EPIC study and methods in detail.

\section{Study subjects}

We describe data from the female participants in the EPIC cohort, 366,521 women. Excluded from the analyses were women with prevalent cancer at the time of recruitment and women who had not completed the dietary or nondietary questionnaires. Data for individuals in the top and bottom $1 \%$ of the ratio of energy intake to estimated energy requirement (calculated from age, sex and bodyweight) were excluded from the analyses to reduce the effect of implausible extreme values. Cases with noninvasive breast cancer at the time of diagnosis were excluded from the cohort. In addition, one Swedish centre (Umeå) and one Dutch centre (Bilthoven) were excluded from the analyses because of missing values for some reproductive adjustment variables. This left 310,671 participants for analyses. In the sub-analyses of fatty and lean fish, one Italian centre (Naples) and both the German centres (Heidelberg and Potsdam) were excluded because of lack of sufficient detail in the questionnaire for classifying fish consumption into lean and fatty fish, leaving 277,834 participants in the analyses.

\section{Diet and lifestyle questionnaires}

Dietary data were obtained using different dietary history or food-frequency questionnaires (FFQ), specific for each country, designed to capture local dietary habits and provide high compliance. ${ }^{14}$ To calibrate dietary data collected by different methods, a single 24-hr computerized dietary recall (24-HDR) was performed in a random sample $(8 \%)$ of the EPIC cohort $(36,900$ individuals). ${ }^{15}$ Since our analysis included only women, data from the 24 HDR was available for 18,754 individuals. The aim of the calibration study was to adjust for systematic over- and underreporting of dietary intakes across countries.

We examined total fish consumption (whole fish, fish products, crustaceans/molluscs, roe- and roe products) total lean fish consumption (whole lean fish and lean fish products), and total fatty fish consumption (whole fatty fish and fatty fish products). Lean fish was classified as fish with less than $4 \%$ fat (e.g., cod, haddock and plaice) and fatty fish as with $4 \%$ fat and above (e.g., salmon, trout, herring and mackerel). Fish products included items coated in batter, breadcrumbs or pastry, roe and roe-products, preserved fish and minced fish products. ${ }^{13}$ We did not distinguish between whole fish and fish products because only a few centres reported fish products, and for some of the centres, it was not possible to separate the fish products from whole fish. Neither did we examine crustacean/molluscs $(8.0 \%$ of the total fish consumption in the 
questionnaires and $10.7 \%$ in the recall) nor roe- and roe products (1.8\% in questionnaire and $1.5 \%$ in recall) separately, since the consumption of these products were limited. Questions about fish consumption in the questionnaires varied considerably between centres and countries, from simple questions on whether participants ate fish and the frequency and portion size to more detailed information on type and amount of fish eaten, cooking method and seasonal variability.

Lifestyle questionnaires included questions about reproductive history, use of oral contraceptives and hormonal replacement therapy, education, socio-economic status, occupation, history of previous illness, physical activity, alcohol consumption and smoking status.

\section{End points}

Follow-up was based on population cancer registries in 7 of the participating countries (Denmark, Italy, the Netherlands, Norway, Spain, Sweden, and the UK) and on a combination of methods including health insurance, cancer and pathology registries, and active follow-up through study subjects and their next-of-kin in 3 countries (France, Germany, and Greece).

The women were followed from enrolment (1992-98) until first breast cancer diagnosis, death, emigration or end of the follow-up period. By the end of March 2004, 4,776 invasive breast cancers had been reported to the International Agency for Research on Cancer (IARC), Lyon, based on information of complete followup data from December 1999 (Turin) to March 2004 (Potsdam) (median for follow-up: 6.4 yr). The 10th Revision of the International Statistical Classification of Diseases, Injuries and Causes of Death was used with breast cancer defined as C50. Only invasive breast cancer cases were included.

\section{Statistical methods}

Hazard ratios (HR) and their 95\% CI were estimated using the Cox proportional regression model. Attained age was used as the primary time variable in the Cox regression models. Time of follow-up was included as a time-dependent variable in the models to take into account possible calendar effects. ${ }^{16}$ The analyses were stratified by centre to control for effects related to different follow-up procedures and questionnaire design. France was included as a single centre, as dietary assessment and follow-up procedures were the same throughout the country, as was the case for Norway. The UK Oxford centre was divided into two, one for the general population and one for the health-conscious participants.

In addition, the results were adjusted by including the following covariates in the models: estimated energy intake (continuous) divided into energy from fat and energy from carbohydrates and proteins, alcohol intake (abstainers, $<15 \mathrm{~g} /$ day, $15-30 \mathrm{~g} / \mathrm{day}, \geq 30 \mathrm{~g} /$ day), weight (continuous), height (continuous), age at menarche $(\leq 11,12,13,14, \geq 15)$, age at first and number of full-term pregnancies (FTP) (nulliparous, $<20$ and 1 FTP, 20-29 and 1 FTP, $>30$ and 1 FTP, $<20$ and $2-3$ FTP, $20-29$ and $2-3$ FTP,$\geq 30$ and $2-3$ FTP, $<20$ and $>3$ FTP, $20-29$ and $>3$ FTP, $>30$ and $>3$ FTP, at least one FTP unknown age or number), current use of hormone replacement therapy (HRT) (yes/no), current use of oral contraceptives (OC) (yes/no), menopausal status (post-/pre-/peri-menopausal), and two variables for interaction between menopausal status and weight. Subjects with missing values for one or more of the adjustment variables were excluded from the analyses.

Fish consumption was divided into EPIC-wide quintiles based on the FFQ. To calculate the p-value for a trend along the consumption categories, an ordinal variable was created by assigning consecutive integers to values of the categorized variable. Models with fish consumption as a continuous variable, calculated in grams per day, were also examined.

To correct for centre-specific bias and regression dilution within each centre stratum, the 24-HDR values for participants of the calibration study were regressed on their main study dietary questionnaire values, providing regression coefficients for total fish consumption. ${ }^{17,18}$ Age at recruitment, weight, body mass index and
TABLE I - DESCRIPTION OF THE EPIC COHORT

\begin{tabular}{|c|c|c|c|c|c|}
\hline \multirow[b]{2}{*}{ Country } & \multicolumn{5}{|c|}{ Age at enrolment } \\
\hline & $\begin{array}{l}<35 \\
\text { years }\end{array}$ & $\begin{array}{l}35-44 \\
\text { years }\end{array}$ & $\begin{array}{c}45-54 \\
\text { years }\end{array}$ & $\begin{array}{l}55-64 \\
\text { years }\end{array}$ & $\begin{array}{l}65+ \\
\text { years }\end{array}$ \\
\hline \multicolumn{6}{|l|}{ France } \\
\hline Case & & 111 & 889 & 530 & 79 \\
\hline Incidence rate ${ }^{1}$ & & 182.7 & 290.0 & 333.0 & 265.2 \\
\hline \multicolumn{6}{|l|}{ Italy } \\
\hline Case & 0 & 94 & 204 & 156 & 17 \\
\hline Incidence rate ${ }^{1}$ & 0.0 & 186.4 & 266.5 & 290.8 & 367.1 \\
\hline \multicolumn{6}{|l|}{ Spain } \\
\hline Case & 2 & 63 & 90 & 67 & 2 \\
\hline Incidence rate ${ }^{1}$ & 112.5 & 101.5 & 151.5 & 175.0 & 134.2 \\
\hline \multicolumn{6}{|l|}{ United Kingdom } \\
\hline Case & 11 & 66 & 201 & 152 & 104 \\
\hline Incidence rate ${ }^{1}$ & 17.1 & 119.3 & 260.4 & 306.8 & 287.8 \\
\hline \multicolumn{6}{|l|}{ The Netherlands } \\
\hline Case & & & 138 & 157 & 63 \\
\hline Incidence rate ${ }^{1}$ & & & 279.1 & 296.5 & 338.2 \\
\hline \multicolumn{6}{|l|}{ Greece } \\
\hline Case & 1 & 7 & 13 & 12 & 11 \\
\hline Incidence rate $^{1}$ & 21.7 & 57.8 & 101.4 & 86.0 & 89.9 \\
\hline \multicolumn{6}{|l|}{ Germany } \\
\hline Case & 1 & 54 & 94 & 142 & 5 \\
\hline Incidence rate ${ }^{1}$ & 143.6 & 87.0 & 194.4 & 290.0 & 220.4 \\
\hline \multicolumn{6}{|l|}{ Sweden } \\
\hline Case & & 3 & 125 & 141 & 53 \\
\hline Incidence rate $^{1}$ & & 1061 & 275.1 & 351.6 & 280.9 \\
\hline \multicolumn{6}{|l|}{ Denmark } \\
\hline Case & & & 278 & 438 & 7 \\
\hline Incidence rate ${ }^{1}$ & & & 348.5 & 400.3 & 288.6 \\
\hline \multicolumn{6}{|l|}{ Norway } \\
\hline Case & & 39 & 147 & 9 & \\
\hline Incidence rate ${ }^{1}$ & & 121.2 & 208.2 & 173.0 & \\
\hline \multicolumn{6}{|l|}{ All countries } \\
\hline Case & 15 & 437 & 2179 & 1804 & 341 \\
\hline Incidence rate $^{1}$ & 20.5 & 130.4 & 263.8 & 315.8 & 269.6 \\
\hline
\end{tabular}

${ }^{1}$ Per 100,000 person years.

season in which the FFQ data was collected were included as covariates in the model. In addition centre was included in the calibration model as a main effect to ensure correction for between-centre measurement errors. Country-specific interaction terms were included to take into account specificity of dietary measurement accuracy and range of intake. Estimation of regression coefficients was weighted for season and day (weekday/weekend) of the 24-HDR measurements.

The regression intercepts and slopes that were obtained from the calibration study questionnaire were then applied to the main study questionnaire to obtain individual predicted values of dietary exposure for all participants. Subjects with zero values in the dietary questionnaires were excluded from the calibration model in the calculation of predicted values and had an imputed predicted value of zero. Cox regression models were then conducted using the predicted values for each individual. An indicator variable (nonconsumer/consumer) was included in the disease model. The same covariates were included in disease models using calibrated values as for the uncalibrated model. All analyses were performed using SAS version 8.02.

\section{Results}

In the $1,932,110$ person years of follow-up since 1992, 4,776 invasive breast cancers had been reported to the IARC database by March 2004. Table I shows the numbers of invasive breast cancer cases included in this analysis according to country and age and the incidence rate per 100,000 person years for each age group. Table II gives more detailed information about the cohort, according to the adjustment variables used in the analyses. A slightly higher percentage of abstainers or low alcohol consumers 
TABLE II - FISH CONSUMPTION BY EPIC-WIDE QUINTILES AND CHARACTERISTICS OF THE WOMEN

\begin{tabular}{|c|c|c|c|c|c|}
\hline & \multicolumn{5}{|c|}{ Fish consumption by EPIC wide quintiles } \\
\hline & $\mathrm{Q} 1(N=62454)$ & $\mathrm{Q} 2(N=61814)$ & $\mathrm{Q} 3(N=62135)$ & $\mathrm{Q} 4(N=62314)$ & $\mathrm{Q} 5(N=62134)$ \\
\hline \multicolumn{6}{|l|}{ Alcohol $^{1}$} \\
\hline Abstainers & $9,431(18.7)$ & $9,850(19.5)$ & $9,474(18.8)$ & $10,287(20.4)$ & $11,355(22.5)$ \\
\hline $0-14.9 \mathrm{~g} /$ day & $43,522(20.9)$ & $41,132(19.8)$ & $41,316(19.9)$ & $39,917(19.2)$ & $42,041(20.2)$ \\
\hline $15.0-29.9 \mathrm{~g} / \mathrm{day}$ & $6,578(19.0)$ & $7,310(21.1)$ & $7,439(21.5)$ & $7,674(22.2)$ & $5,608(16.2)$ \\
\hline $30.0+\mathrm{g} / \mathrm{day}$ & $2,923(16.5)$ & $3,522(19.9)$ & $3,906(22.0)$ & $4,256(24.0)$ & $3,130(17.6)$ \\
\hline \multicolumn{6}{|l|}{ Age at menarche ${ }^{1}$} \\
\hline$\leq 11$ & $9,089(19.6)$ & $9,143(19.7)$ & $9,639(20.8)$ & $9,569(20.6)$ & $8,907(19.2)$ \\
\hline$\overline{12}$ & $13,575(20.6)$ & $13,647(20.7)$ & $13,169(20.0)$ & $12,761(19.4)$ & $12,720(19.3)$ \\
\hline 13 & $16,100(20.3)$ & $15,551(19.6)$ & $15,882(20.0)$ & $15,752(19.8)$ & $16,181(20.4)$ \\
\hline 14 & $13,007(19.6)$ & $13,027(19.6)$ & $13,322(20.0)$ & $13,404(20.2)$ & $13,745(20.7)$ \\
\hline$\geq 15$ & 9,921 (20.4) & $9,777(20.1)$ & $9,308(19.2)$ & $9,821(20.2)$ & $9,770(20.1)$ \\
\hline \multirow{2}{*}{\multicolumn{6}{|c|}{ Parity (FTP)/ age at 1 st birth ${ }^{1}$}} \\
\hline & & & & & \\
\hline Nulliparous & $13,925(31.3)$ & $8,227(18.5)$ & $7,858(17.6)$ & $7,288(16.4)$ & $7,232(16.2)$ \\
\hline $1 /<20$ & $515(22.2)$ & $452(19.5)$ & $403(17.4)$ & $445(19.2)$ & $500(21.6)$ \\
\hline $1 / 20-29$ & $6,199(21.0)$ & $6,253(21.2)$ & $5,988(20.3)$ & $5,833(19.8)$ & $5,254(17.8)$ \\
\hline $1 / \geq 30$ & $3,066(20.7)$ & $3,034(20.5)$ & $3,147(21.2)$ & $2,939(19.8)$ & $2,627(17.7)$ \\
\hline $2-3 /<20$ & $2,574(17.3)$ & $2,871(19.3)$ & $2,717(18.3)$ & $2,888(19.5)$ & $3,796(25.6)$ \\
\hline $2-3 / 20-29$ & $25,697(17.2)$ & $29,780(19.9)$ & $30,640(20.5)$ & $31,432(21.0)$ & $31,862(21.3)$ \\
\hline $2-3 / \geq 30$ & $3,798(19.8)$ & $4,017(20.9)$ & $3,971(20.7)$ & $3,762(19.6)$ & $3,631(18.9)$ \\
\hline $4+/<20$ & $733(17.7)$ & $762(18.4)$ & $780(18.8)$ & $867(20.9)$ & $1,004(24.2)$ \\
\hline $4+/ 20-29$ & $4,100(19.5)$ & $4,216(20.0)$ & $4,092(19.4)$ & $4,290(20.4)$ & $4,372(20.7)$ \\
\hline $4+/ \geq 30$ & $221(24.2)$ & $202(22.1)$ & $166(18.2)$ & $156(17.1)$ & $167(18.3)$ \\
\hline Have had FTP, age or number unknown & $518(16.1)$ & $671(20.9)$ & $822(25.5)$ & $710(22.1)$ & $497(15.4)$ \\
\hline Unknown if ever had FTP & $1,108(16.5)$ & $1,329(19.8)$ & $1,551(23.1)$ & $1,524(22.7)$ & $1,192(17.8)$ \\
\hline \multicolumn{6}{|l|}{ Use of OC } \\
\hline Missing & $261(19.1)$ & $283(20.7)$ & $299(21.8)$ & $301(22.0)$ & $225(16.4)$ \\
\hline Not current pill user & $5,6081(19.4)$ & $57,354(19.8)$ & $57,923(20.0)$ & $58,399(20.2)$ & $59,390(20.5)$ \\
\hline Current pill user & $6,112(30.3)$ & $4,177(20.7)$ & $3,913(19.4)$ & $3,434(17.0)$ & $2,519(12.5)$ \\
\hline \multicolumn{6}{|l|}{ Menopausal status ${ }^{1}$} \\
\hline Pre & $22,543(27.3)$ & $17,489(21.2)$ & $16,192(19.6)$ & $14,577(17.7)$ & $11,642(14.1)$ \\
\hline Post & $27,192(18.9)$ & $29,464(20.5)$ & $29,802(20.7)$ & $29,846(20.8)$ & $27,492(19.1)$ \\
\hline Peri & $9,368(14.3)$ & $10,976(16.8)$ & $12,147(18.6)$ & $13,802(21.1)$ & $19,180(29.3)$ \\
\hline Unknown & $3,351(17.7)$ & $3,885(20.5)$ & $3,994(21.1)$ & $3,909(20.6)$ & $3,820(20.1)$ \\
\hline \multicolumn{6}{|l|}{ Use of $\mathrm{HRT}^{1}$} \\
\hline Missing & $3,205(25.3)$ & $2,798(22.1)$ & $2,233(17.6)$ & $2,058(16.2)$ & $2,386(18.8)$ \\
\hline Not current HRT user & $49,219(21.4)$ & $46,086(20.1)$ & $44,969(19.6)$ & $45,057(19.6)$ & $44,387(19.3)$ \\
\hline Current HRT user & $10,030(14.7)$ & $12,930(18.9)$ & $14,933(21.9)$ & $15,019(22.0)$ & $15,361(22.5)$ \\
\hline \multicolumn{6}{|l|}{ Age at recruitment ${ }^{1}$} \\
\hline Age $<35$ & $7,176(52.0)$ & $2,026(14.7)$ & $1,899(13.8)$ & $1,490(10.8)$ & $1,219(8.8)$ \\
\hline Age $35-44$ & $1,2621(21.4)$ & $11,893(20.1)$ & $10,840(18.3)$ & $10,975(18.6)$ & $12,784(21.6)$ \\
\hline Age 45-54 & $2,1612(16.4)$ & $25,150(19.1)$ & $26,417(20.0)$ & $27,479(20.9)$ & $31,113(23.6)$ \\
\hline Age 55-64 & $1,6248(19.1)$ & $17,910(21.0)$ & $18,365(21.6)$ & $18,384(21.6)$ & $14,276(16.8)$ \\
\hline Age $65+$ & $4,797(23.1)$ & $4,835(23.3)$ & $4,614(22.2)$ & $3,806(18.3)$ & $2,742(13.2)$ \\
\hline \multicolumn{6}{|l|}{ Energy $^{2}$} \\
\hline From proteins and carbohydrates & $11.2(3.3)$ & $11.6(3.3)$ & $12.2(3.4)$ & $12.6(3.5)$ & $12.6(3.6)$ \\
\hline From fat & $6.4(2.3)$ & $7.0(2.4)$ & $7.2(2.5)$ & $7.4(2.5)$ & $7.3(2.5)$ \\
\hline Height $^{2}$ & $162.3(6.9)$ & $161.3(6.7)$ & $161.6(6.6)$ & $161.9(6.6)$ & $163.3(6.8)$ \\
\hline Weight $^{2}$ & $65.1(11.7)$ & $65.6(11.7)$ & $65.6(11.7)$ & $66.0(11.5)$ & $67.2(11.7)$ \\
\hline $\operatorname{Age}^{2}$ & $49.6(11.6)$ & $51.8(9.4)$ & $52.1(9.2)$ & $52.0(8.7)$ & $51.0(8.0)$ \\
\hline Years of follow up ${ }^{2}$ & $6.4(1.9)$ & $6.4(2.0)$ & $6.5(1.9)$ & $6.4(2.0)$ & $5.4(2.2)$ \\
\hline
\end{tabular}

${ }^{1}$ Number of subjects (row percent).-- ${ }^{2}$ Mean (SD).

is seen in the highest quintile (highest consumption of fish). The distribution of age at first birth is shifted to younger ages among those with higher fish consumption. A higher proportion of perimenopausal women, not current users of OC, and current users of HRT were found in the 5 th quintile. Mean age for the women in the 5 th quintile was $51 \mathrm{yr}$.

Table III shows the mean intake of fish consumption within each EPIC-wide quintile of intake, for the women included in the calibration study. The means were estimated from both 24-HDR and FFQ data. We assumed data from the 24-HDR gave a more accurate estimate of the mean fish consumption than data from the questionnaires, based on the assumption that the 24-HDR data provide an unbiased estimate of intake because it corrects for between centre/country measurement errors. The table indicates that the questionnaire underestimates in the lowest quintiles and overestimates in the highest quintiles. This is probably due to the different level of detail of the questions in the centre/country specific questionnaires, and also that the FFQ requires respondents to integrate habitual consumption over quite a long period of time, thereby yielding a wider distribution of intake compared with the 24-HDR. Mean intake of total fish was $\sim 4$-fold higher in the upper quintile than in the lowest quintile based on the 24-HDR data. For lean fish intake, the difference was more than 2-fold, and for fatty fish intake, the difference was more than 3 -fold. Table III also shows the mean intake of fish consumption for the different countries. The means were estimated from questionnaire data only as means from the $24-H D R$ recalls have been reported earlier. ${ }^{13}$

Intake of total fish in relation to breast cancer risk, of total fish by pre- and postmenopausal women respectively, and of lean and fatty fish respectively, stratified by centre, are found in Table IV. The analyses are based on the uncalibrated FFQ data. For total fish, we found no significant association between fish intake and breast cancer risk neither among all women nor after stratification according to menopausal status. When examining lean and fatty fish separately, we found a significant association in the highest quintile for fatty fish (HR 1.16, 95\% CI 1.05-1.29) when unad- 
TABLE III - MEAN FISH INTAKES WITHIN EACH EPIC-WIDE QUINTILE OF INTAKE ${ }^{1}$ AND MEAN FISH INTAKE

\begin{tabular}{|c|c|c|c|c|c|c|}
\hline \multirow{2}{*}{ Foodgroup } & \multirow{2}{*}{ Mean (g/day) } & \multicolumn{5}{|c|}{ EPIC-wide quintiles } \\
\hline & & Q1 & Q2 & Q3 & $\mathrm{Q} 4$ & Q5 \\
\hline \multicolumn{7}{|l|}{ Total fish ${ }^{3}$} \\
\hline Recall & 32.79 & 13.36 & 24.77 & 33.14 & 41.09 & 54.05 \\
\hline FFQ & 38.37 & 5.54 & 17.94 & 30.50 & 48.00 & 96.77 \\
\hline \multicolumn{7}{|l|}{ Lean fish ${ }^{4,6}$} \\
\hline Recall & 16.26 & 11.25 & 11.18 & 13.93 & 20.43 & 26.26 \\
\hline FFQ & 20.09 & 0.29 & 6.44 & 13.64 & 23.89 & 61.41 \\
\hline \multicolumn{7}{|l|}{ Fatty fish ${ }^{5,6}$} \\
\hline Recall & 11.99 & 6.02 & 9.04 & 11.59 & 13.40 & 19.67 \\
\hline FFQ & 13.01 & 0.28 & 3.72 & 9.03 & 15.82 & 36.21 \\
\hline \multicolumn{7}{|c|}{ Total fish ${ }^{3}$ FFQ } \\
\hline France & 37.46 & 7.58 & 18.13 & 30.42 & 47.87 & 87.28 \\
\hline Italy & 31.29 & 6.80 & 18.19 & 30.48 & 47.57 & 85.12 \\
\hline Spain & 54.82 & 5.16 & 19.12 & 30.78 & 48.42 & 91.85 \\
\hline UK & 37.19 & 1.85 & 18.72 & 30.77 & 47.45 & 89.46 \\
\hline NL & 10.90 & 4.34 & 16.65 & 31.24 & 42.50 & 91.47 \\
\hline Greece & 22.06 & 7.25 & 16.95 & 29.31 & 45.25 & 80.56 \\
\hline Germany & 18.47 & 5.36 & 18.18 & 30.02 & 45.82 & 101.3 \\
\hline Sweden & 39.38 & 3.87 & 18.62 & 30.66 & 47.89 & 84.27 \\
\hline Denmark & 45.91 & 7.56 & 19.21 & 31.09 & 48.54 & 81.70 \\
\hline Norway & 92.21 & 4.66 & 19.16 & 31.44 & 50.67 & 115.5 \\
\hline
\end{tabular}

${ }^{1}$ Estimated from 24-hr recall and from food frequency questionnaires (FFQ) for women in the calibration study. $-{ }^{2}$ Estimated from FFQ only.- ${ }^{3}$ Whole fish, fish products, crustaceans/molluscs, roe- and roe products.- ${ }^{4}$ Whole lean fish and lean fish products. $-{ }^{5}$ Whole fatty fish and fatty fish products.- ${ }^{6}$ The Italian centre, Naples and the two German centres are excluded.

TABLE IV - BREAST CANCER RISK IN RELATION TO FISH CONSUMPTION, STRATIFIED BY CENTRE (ANALYSES BASED ON UNCALIBRATED FFQ DATA)

\begin{tabular}{|c|c|c|c|c|c|c|}
\hline & Q1 & Q2 & Q3 & Q4 & Q5 & $\begin{array}{l}p \text {-value } \\
\text { for trend }\end{array}$ \\
\hline \multicolumn{7}{|c|}{ Total fish consumption } \\
\hline $\begin{array}{l}\text { No. cases/ } \\
\text { person years }\end{array}$ & $869 / 398,328$ & $972 / 397,270$ & $1,051 / 403,964$ & $1,023 / 397,335$ & $861 / 335,210$ & \\
\hline $\mathrm{HR}^{1}$ & 1 & $1.01(0.92-1.11)$ & $1.04(0.94-1.14)$ & $1.03(0.93-1.14)$ & $1.12(1.01-1.25)$ & 0.05 \\
\hline $\mathrm{HR}^{2}$ & 1 & $0.99(0.90-1.10)$ & $0.98(0.89-1.09)$ & $0.98(0.88-1.09)$ & $1.07(0.95-1.20)$ & 0.36 \\
\hline \multicolumn{7}{|c|}{ Total fish premenopausal women } \\
\hline $\begin{array}{l}\text { No. cases/ } \\
\text { person years }\end{array}$ & $162 / 133,049$ & $155 / 105,541$ & $191 / 100,177$ & $158 / 91,144$ & $120 / 69,523$ & \\
\hline $\mathrm{HR}^{1}$ & 1 & $0.88(0.70-1.10)$ & $1.08(0.87-1.36)$ & $1.02(0.80-1.29)$ & $1.11(0.85-1.43)$ & 0.24 \\
\hline $\mathrm{HR}^{3}$ & 1 & $0.89(0.71-1.12)$ & $1.08(0.86-1.36)$ & $1.03(0.81-1.31)$ & $1.11(0.84-1.45)$ & 0.27 \\
\hline \multicolumn{7}{|c|}{ Total fish postmenopausal women } \\
\hline $\begin{array}{l}\text { No. cases/ } \\
\text { person years }\end{array}$ & $504 / 179,455$ & $561 / 189,155$ & $553 / 193,487$ & $576 / 195,311$ & $506 / 158,886$ & \\
\hline $\mathrm{HR}^{1}$ & 1 & $1.05(0.93-1.19)$ & $0.98(0.85-1.11)$ & $1.00(0.87-1.14)$ & $1.16(1.00-1.33)$ & 0.15 \\
\hline $\mathrm{HR}^{4}$ & 1 & $1.03(0.90-1.17)$ & $0.92(0.80-1.05)$ & $0.95(0.82-1.09)$ & $1.10(0.95-1.28)$ & 0.52 \\
\hline \multicolumn{7}{|c|}{ Lean fish consumption ${ }^{5}$} \\
\hline $\begin{array}{l}\text { No. cases/ } \\
\text { person years }\end{array}$ & $885 / 378,895$ & $1,011 / 369,550$ & $985 / 362,733$ & $905 / 347,799$ & $649 / 277,837$ & \\
\hline $\mathrm{HR}^{1}$ & 1 & $1.05(0.96-1.15)$ & $1.07(0.98-1.18)$ & $1.08(0.98-1.19)$ & $1.10(0.99-1.23)$ & 0.06 \\
\hline $\mathrm{HR}^{2}$ & 1 & $1.03(0.93-1.14)$ & $1.04(0.94-1.15)$ & $1.06(0.95-1.17)$ & $1.07(0.95-1.21)$ & 0.20 \\
\hline \multicolumn{7}{|c|}{ Fatty fish consumption ${ }^{5}$} \\
\hline $\begin{array}{l}\text { No. cases/ } \\
\text { person years }\end{array}$ & $753 / 352,824$ & $933 / 357,634$ & $917 / 348,858$ & $921 / 350,699$ & $911 / 326,799$ & \\
\hline $\mathrm{HR}^{1}$ & 1 & $1.06(0.96-1.17)$ & $1.07(0.96-1.18)$ & $1.06(0.95-1.17)$ & $1.16(1.05-1.29)$ & 0.01 \\
\hline $\mathrm{HR}^{2}$ & 1 & $1.03(0.93-1.15)$ & $1.03(0.93-1.15)$ & $1.00(0.90-1.12)$ & $1.13(1.01-1.26)$ & 0.10 \\
\hline
\end{tabular}

${ }^{1}$ Stratified by centre. $-{ }^{2}$ Stratified by centre, adjusted for time of follow-up, energy intake (EI) from fat, EI from carbohydrates and protein, alcohol intake, height, weight, age at menarche, number of full-term pregnancies (FTP) and age at first FTP, current use of hormone replacement therapy (HRT), current use of oral contraceptives (OC) and menopausal status. ${ }^{3}$ Stratified by centre, adjusted for time of follow-up, EI from fat, EI from carbohydrates and protein, alcohol intake, height, weight, age at menarche, number of FTP and age at first FTP and current use of OC. $-{ }^{4}$ Stratified by centre, adjusted for time of follow-up, EI from fat, EI from carbohydrates and protein, alcohol intake, height, weight, age at menarche, number of FTP and age at first FTP, current use of HRT and current use of OC. $-{ }^{5}$ Excluded German centres and the Italian centre Naples. ${ }^{-}$Numbers for analysis only stratified by centre. For adjusted analysis the numbers will be smaller due to exclusion of subjects with missing values for adjustment variables.

justed, and HR 1.13 (95\% CI 1.01-1.26) after adjustment, although the test for trend was not significant after adjustment $(p$ $=0.10)$. The estimated HR did not change after performing the analyses without energy adjustment.

The relative risks for breast cancer in relation to total fish consumption in the different countries are shown in Figure 1. Though fish consumption appeared to be associated with a slight increase in breast can- cer risk in some countries, the data should be interpreted with caution because of the small number of cases accruing from a short follow-up time. The country with most cases and longest follow-up, France, showed neither evidence for a protective effect nor increased risk between fish consumption and breast cancer ( $p$ for trend 0.83 ).

Figure 2 presents the continuous original (uncalibrated) and the deattenuated (calibrated) risk estimates for breast cancer and total 


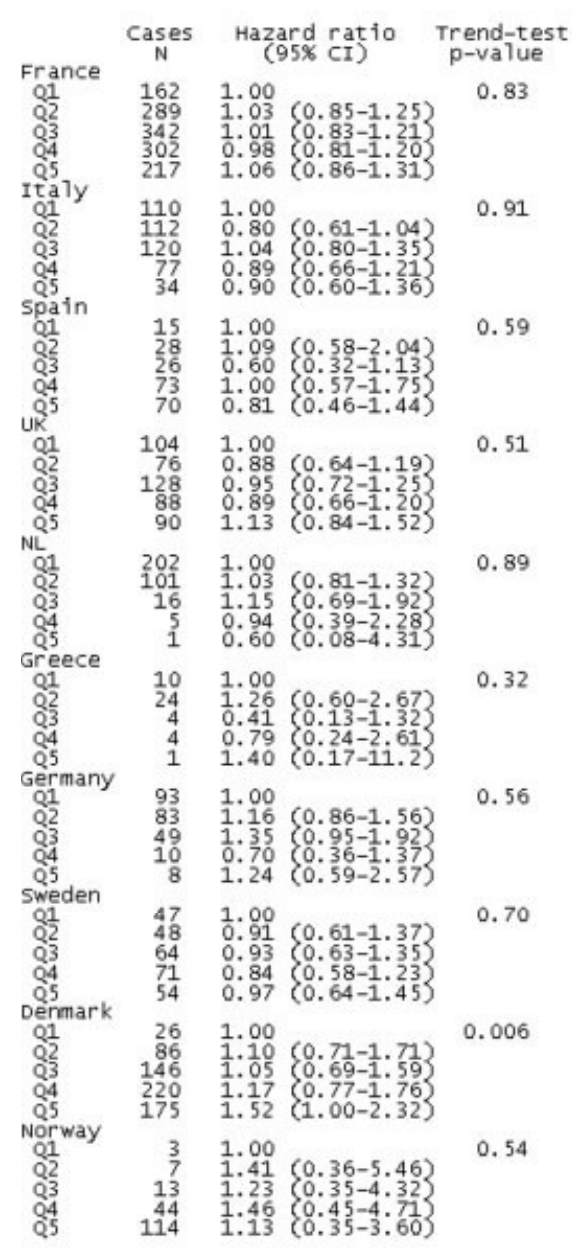

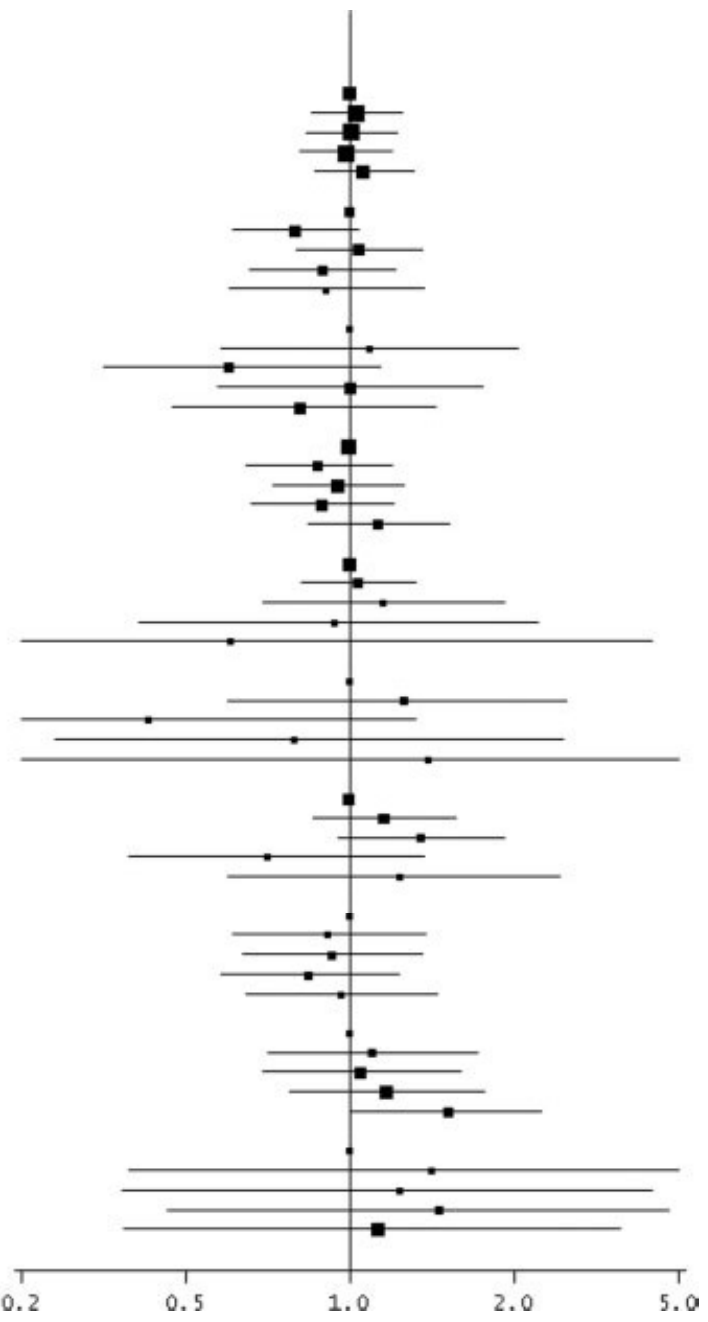

Figure 1 - Breast cancer risk by EPIC-wide quintiles of total fish consumption in each country. Cox PH model stratified by centre, adjusted for time of follow-up, energy intake from fat, energy intake from carbohydrates and protein, alcohol intake, height, weight, age at menarche, number of FTP and age at first full-term pregnancy, current use of HRT, current use of OC and menopausal status.

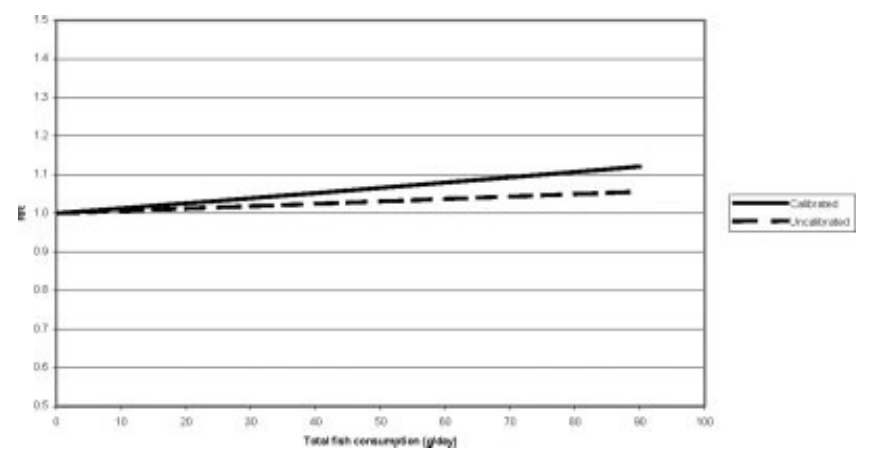

FigURE 2 - Relative risk for breast cancer according to total fish consumption (g/day). Cox PH model stratified by centre, adjusted for time of follow-up, energy intake from fat, energy intake from carbohydrates and protein, alcohol intake, height, weight, age at menarche, number of FTP and age at first full-term pregnancy, current use of HRT, current use of OC and menopausal status.

fish consumption. The uncalibrated $\beta$-coefficient for total fish consumption $(10 \mathrm{~g} /$ day $)$ was $0.0060(\mathrm{SE}=0.0056, p=0.28)$. The calibrated $\beta$-coefficient was 0.0127 ( $\mathrm{SE}=0.0163, p=0.44)$. This is equal to HR $1.01,95 \%$ CI $0.99-1.02$ and HR $1.01,95 \%$ CI $0.98-1.05$ based on uncalibrated and calibrated data respectively. The standard error and the CI of the deattenuated estimates given here are in fact too small, since the uncertainty related to measure- ment error correction has not been taken into account. We could find a more conservative estimate of the standard error by bootstrap sampling, but since we found no evidence for a relationship in the first place that was not relevant here.

\section{Discussion}

The present study found no evidence of an inverse association between total fish consumption and breast cancer risk. When examining separately lean and fatty fish, there was still no association with breast cancer risk. Though women in the top quintile of fatty fish did show a statistically significant positive association with breast cancer risk, the test for trend was not significant after adjustment. We also found no associations between fish intake and breast cancer risk in this study after stratification according to menopausal status.

The lack of association between fish consumption and breast cancer risk does not concur with the studies of Gago-Dominguez et al., ${ }^{8}$ Key et al., ${ }^{19}$ Ambrosone et al. ${ }^{20}$ and Hirose et al. ${ }^{9}$ It is, however, consistent with the pooled analysis of cohort studies by Missmer et al. ${ }^{21}$ The advantages of our study are its size: the EPIC study is as far as we know the largest prospective cohort study with detailed dietary data, and the wide range in fish intake. The study includes participants from the Scandinavian countries in the north of Europe to the Mediterranean countries in the south. It is therefore reasonable to believe that the results from this study are more reliable than the results from smaller studies, often only carried out in one region or one country. 
In this study, we were not able to examine the effect of omega 6 $(n-6) / n-3$ ratio in the diet. Nor were we able to examine the consumption of n-3 polyunsaturated fatty acids, since detailed information about content in different foods, and information about use of cod-liver oil or other n-3 supplements is not currently available for most countries in this study. It is possible that fish consumption has an impact on breast cancer risk if fatty acid interaction were taken into account. However, a few epidemiological studies have examined the association between $n-6 / n-3$ ratio and breast cancer risk but the results vary. Three studies, examining fatty acids in serum phospholipids or erythrocyte membrane, found no significant associations, ${ }^{22-24}$ whereas three other studies, examining long chain n-3 and n-6 in adipose tissue, showed inverse associations with breast cancer risk ${ }^{25-27}$, and one study found that among subjects in the lowest quartile of intake of marine n-3 fatty acids, a positive association between $n-6$ fatty acids and breast cancer risk was observed. ${ }^{8}$ Likewise, several studies on n-3 fatty acids have also found no significant association with breast cancer, $7,22,24$ whereas other ${ }^{25}$ found an inverse association. Although the results from the studies examining $n-3 / n-6$ in adipose tissue are more convincing than the other studies, since this is the best measure for long term fish intake, since they examined long chain n-3 (marine $\mathrm{n}-3$ ) and not total $\mathrm{n}-3$, the evidence for an association between breast cancer and $n-6 / n-3$ ratio, or n-3 intake and breast cancer risk, remains unclear.

Another limitation of this study is the different level of detail available from the questionnaires concerning fish in the centres or countries, which made it difficult to distinguish between different types of fish and fish products. Separation of fish products from whole fish might influence our findings if relationships with breast cancer differed. The same is the case for cooking methods and how fish is consumed: with sauces, with breadcrumbs, smoked, salted, etc. Since this information was not available for most of the countries, we had to confine ourselves to looking at total, lean and fatty fish only.

Two studies, one case control study from Sweden ${ }^{10}$ and one cohort study from Denmark ${ }^{12}$, have looked at the association with breast cancer separately with lean and fatty fish. The case control study found only a weak, nonsignificant, protective association for fatty fish, but not lean fish. The Danish study, a sub study of the Danish EPIC cohort, found an increased risk associated with total fish. This is in accordance with the observations in Figure 1 for Denmark ( $p$ for trend 0.006). Our study found a slightly increased risk for fatty fish consumption in the 5th quintile, although the test for trend was not significant. In the Danish study, no associations were found according to type of fish.

If there is a protective effect of fish consumption on breast cancer risk, it may be that this effect is counterbalanced by the negative effect of contaminants. Among contaminants found in fish are mercury, ${ }^{28}$ dioxins and PCB. ${ }^{29}$ The amount and type of contaminants differs according to were the fish is caught, fish species and methods of preparation. Most of the contaminants accumulate in the fat; therefore, contaminants are more likely in fatty fish. We did not take contaminants in fish into consideration when we did the analysis. However, in addition to the questionnaires and the 24-HDR, the EPIC study has collected blood samples from 385,747 of the 519,978 study participants ${ }^{14}$ and will therefore have the opportunity to study the levels of different contaminants in plasma or serum in future analyses.

A case-control study by Ronco et al. ${ }^{30}$ found a significant increased breast cancer risk for consumption of fried fish and a significant inverse association for fish that was not fried, indicating that the cooking method may be important. Heterocyclic amines (HA) and polycyclic aromatic hydrocarbons (PAH) formed during preparation of the fish at high temperatures may be one of the reasons. Rohrmann et al., ${ }^{31}$ studied the different preparation methods for meat and fish in the 24-HDR in EPIC. They found that hightemperature cooking methods were more often used in northern Europe and less often used in the EPIC cohorts of France, northern Italy, Greece and southern Spain. Incidence rates of breast cancer are higher in the northern and western countries of Europe than in the south. Several studies that have focused on high-temperature cooking methods have shown an increased risk of breast cancer. $^{20,32,33}$ This may be in line with the slightly increased risks we see in Germany, Norway and Denmark (Fig. 1). EPIC-Spain published recently a table with information on food concentration of some carcinogenic compounds in food.$^{34}$ This table gives information on HA and PAH in fish and makes it, to a certain degree, possible to take these contaminants into consideration. However, most of the questionnaires were lacking information on cooking methods for fish. To give a good estimates of the intake of HA or PAH, one would have to develop a questionnaire on cooking methods for fish and degree of browning that could be applied in all EPIC countries. ${ }^{31}$ Since we found no association between fish and breast cancer for any of the countries, there is no reason to believe that the results would differ substantially by adjusting for these compounds.

There are other additional considerations in fish intake. Fish is the best dietary source for vitamin $\mathrm{D}$, and is also a good source of other vitamins (vitamin A and B), minerals (calcium, phosphorus, iron) and trace elements (selenium, iodine, zinc). All of these components could be associated with breast cancer risk. It is hypothesized that vitamin $\mathrm{D}$ plays a protective role in reducing breast cancer risk. ${ }^{35,36}$ If these components have any beneficial effect on breast cancer risk, it may be that they are needed in higher concentrations than are found in fish.

There is no clear evidence for an association between fish consumption and breast cancer risk according to this study. However, one must be careful to draw any conclusions, since the follow-up time for this study is rather short. Future studies should also try to focus on the fatty acid interaction, especially the $n-6 / n-3$ ratio in the diet, and if possible consider potential contaminants.

\section{References}

1. Diet, nutrition, and the prevention of chronic diseases. Report of a joint WHO/FAO expert consultation,916 ed. Geneva: World Health Organization, 2003

2. de Deckere EA. Possible beneficial effect of fish and fish n-3 polyunsaturated fatty acids in breast and colorectal cancer. Eur J Cancer Prev 1999;8:213-21.

3. Fernandez E, Chatenoud L, La Vecchia C, Negri E, Franceschi S. Fish consumption and cancer risk. Am J Clin Nutr 1999;70(1):85-90.

4. Terry PD, Rohan TE, Wolk A. Intakes of fish and marine fatty acids and the risks of cancers of the breast and prostate and of other hormone-related cancers: a review of the epidemiologic evidence. Am J Clin Nutr 2003;77:532-43.

5. Rose DP, Connolly JM. Regulation of tumor angiogenesis by dietary fatty acids and eicosanoids. Nutr Cancer 2000;37(2):119-27.

6. Rose DP, Connolly JM. Omega-3 fatty acids as cancer chemopreventive agents. Pharmacol Ther 1999;83:217-44.
7. Holmes MD, Hunter DJ, Colditz GA, Stampfer MJ, Hankinson SE. Association of dietary intake of fat and fatty acids with risk of breast cancer. JAMA 1999;281:914-20.

8. Gago-Dominguez M, Yuan JM, Sun CL, Lee HP, Yu MC. Opposing effects of dietary n-3 and n-6 fatty acids on mammary carcinogenesis: The Singapore Chinese Health Study. Br J Cancer 2003;89: 1686-92.

9. Hirose K, Takezaki T, Hamajima N, Miura S, Tajima K. Dietary factors protective against breast cancer in japanese premenopausal and postmenopausal women. Int J Cancer 2003;107:276-82.

10. Terry P, Rohan TE, Wolk A, Maehle-Schmidt M, Magnusson C. Fish consumption and breast cancer risk. Nutr Cancer 2002;44(1):1-6.

11. Lund E, Engeset D, Alsaker E, Skeie G, Hjartaker A, Lundebye AK, Niebor E. Cancer risk and salmon intake. Science 2004;305:477-8.

12. Stripp C, Overvad K, Christensen J, Thomsen BL, Olsen A, Moller S, Tjonneland A. Fish intake is positively associated with breast cancer incidence rate. J Nutr 2003;133:3664-9. 
13. Welch AA, Lund E, Amiano P, Dorronsoro M, Brustad M, Kumle M, Rodriguez M, Lasheras C, Janzon L, Jansson J, Luben R, Spencer EA, et al. Variability of fish consumption within the 10 European countries participating in the European Investigation into Cancer and Nutrition (EPIC) study. Public Health Nutr 2002;5:1273-85.

14. Riboli E, Hunt KJ, Slimani N, Ferrari P, Norat T, Fahey M, Charrondiere UR, Hemon B, Casagrande C, Vignat J, Overvad K, Tjonneland A, et al. European Prospective Investigation into Cancer and Nutrition (EPIC): study populations and data collection. Public Health Nutr 2002;5:1113-24

15. Slimani N, Kaaks R, Ferrari P, Casagrande C, Clavel-Chapelon F, Lotze G, Kroke A, Trichopoulos D, Trichopoulou A, Lauria C, Bellegotti M, Ocke MC, et al. European Prospective Investigation into Cancer and Nutrition (EPIC) calibration study: rationale, design and population characteristics. Public Health Nutr 2002;5:1125-45.

16. Korn EL, Graubard BI, Midthune D. Time-to-event analysis of longitudinal follow-up of a survey: choice of the time-scale. Am J Epidemiol 1997; 145(1):72-80.

17. Kaaks R, Riboli E, van Staveren W. Calibration of dietary intake measurements in prospective cohort studies. Am J Epidemiol 1995 142:548-56.

18. Rosner B, Willett WC, Spiegelman D. Correction of logistic-regression relative risk estimates and confidence-intervals for systematic within-person measurement error. Stat Med 1989;8:1051-69.

19. Key TJ, Sharp GB, Appleby PN, Beral V, Goodman MT, Soda M, Mabuchi K. Soya foods and breast cancer risk: a prospective study in Hiroshima and Nagasaki, Japan. Br J Cancer 1999;81:1248-56.

20. Ambrosone CB, Freudenheim JL, Sinha R, Graham S, Marshall JR Vena JE, Laughlin R, Nemoto T, Shields PG. Breast cancer risk, meat consumption and N-acetyltransferase (NAT2) genetic polymorphisms. Int J Cancer 1998;75:825-30.

21. Missmer SA, Smith-Warner SA, Spiegelman D, Yaun SS, Adami HO, Beeson WL, van den Brandt PA, Fraser GE, Freudenheim JL, Goldbohm RA, Graham S, Kushi LH, et al. Meat and dairy food consumption and breast cancer: a pooled analysis of cohort studies. Int J Epidemiol 2002;31(1):78-85.

22. Chajes V, Hulten K, van Kappel AL, Winkvist A, Kaaks R, Hallmans G, Lenner P, Riboli E. Fatty-acid composition in serum phospholipid and risk of breast cancer: an incident case-control study in Sweden. Int J Cancer 1999;83:585-90.

23. Vatten LJ, Bjerve KS, Andersen A, Jellum E. Polyunsaturated fatty acid in serum phospholipids and risk of breast cancer: a case-control study from the Janus serum bank in Norway. Eur J Cancer 1993;29A: 532-8.

24. Wirfalt E, Vessby B, Mattisson I, Gullberg B, Olsson H, Berglund G No relations between breast cancer risk and fatty acids of erythrocyte membranes in postmenopausal women of the Malmo Diet Cancer cohort (Sweden). Eur J Clin Nutr 2004;58:761-70.

25. Bagga D, Anders KH, Wang HJ, Glaspy JA. Long-chain n-3-to-n-6 polyunsaturated fatty acid ratios in breast adipose tissue from women with and without breast cancer. Nutr Cancer 2002;42(2):180-5.

26. Maillard V, Bougnoux P, Ferrari P, Jourdan ML, Pinault M, Lavillonniere F, Body G, Le Floch O, Chajes V. N-3 and N-6 fatty acids in breast adipose tissue and relative risk of breast cancer in a case-control study in Tours, France. Int J Cancer 2002;98(1): 78-83.

27. Simonsen N, van't Veer P, Strain JJ, Martin-Moreno JM, Huttunen JK, Navajas JF, Martin BC, Thamm M, Kardinaal AF, Kok FJ, Kohlmeier L.Adipose tissue omega-3 and omega- 6 fatty acid content and breast cancer in the EURAMIC study. European community multicenter study on antioxidants, myocardial infarction, and breast cancer. Am J Epidemiol 1998;147:342-52.

28. Sanzo JM, Dorronsoro M, Amiano P, Amurrio A, Aguinagalde FX Azpiri MA. Estimation and validation of mercury intake associated with fish consumption in an EPIC cohort of Spain. Public Health Nutr 2001;4:981-8.

29. Sjodin A, Hagmar L, Klasson-Wehler E, Bjork J, Bergman A. Influence of the consumption of fatty Baltic Sea fish on plasma levels of halogenated environmental contaminants in Latvian and Swedish men. Environ Health Perspect 2000;108:1035-41.

30. Ronco AL, De Stefani E, Fabra A. White meat intake and the risk of breast cancer: a case-control study in Montevideo, Uruguay. Nutr Res 2003;23(2):151-62

31. Rohrmann S, Linseisen J, Becker N, Norat T, Sinha R, Skeie G, Lund E, Martinez C, Barricarte A, Mattisson I, Berglund G, Welch A, et al Cooking of meat and fish in Europe-results from the European Prospective Investigation into Cancer and Nutrition (EPIC). Eur J Clin Nutr 2002;56:1216-30

32. Sinha R. An epidemiologic approach to studying heterocyclic amines. Mutat Res 2002;506:197-204.

33. Zheng W, Gustafson DR, Sinha R, Cerhan JR, Moore D, Hong CP, Anderson KE, Kushi LH, Sellers TA, Folsom AR. Well-done meat intake and the risk of breast cancer. J Natl Cancer Inst 1998;90:1724-9.

34. Jakszyn P, Ibáñez R, Pera G, García-Closas R, Agudo A, Amiano P, González CA. Food content of potential carcinogens. Barcelona: Catalan Institute of oncology, 2004.

35. Coyle YM. The effect of environment on breast cancer risk. Breast Cancer Res Treat 2004;84:273-88.

36. Robsahm TE, Tretli S, Dahlback A, Moan J. Vitamin D3 from sunlight may improve the prognosis of breast-, colon- and prostate cancer (Norway). Cancer Causes Control 2004;15(2):149-58. 